\title{
Local regulation of the axonal phenotype, a case of merotrophism
}

\author{
FELIPE A. COURT ${ }^{1}$ and JAIME ÁLVAREZ ${ }^{2}$
}

1. San Raffaele Scientific Institute, DIBIT, Milan, Italy; 2. Facultad de Ciencias Biológicas, Pontificia Universidad Católica. Santiago, Chile

\begin{abstract}
In this essay, we show that several anatomical features of the axon, namely, microtubular content, caliber and extension of sprouts, correlate on a local basis with the particular condition of the glial cell, i.e., the anatomy of axons is dynamic, although it is seen usually in its 'normal' state. The occurrence of ribosomes and messenger RNAs in the axon suggests that axoplasmic proteins are most likely synthesized locally, at variance with the accepted notion that they are supplied by the cell body. We propose that the supporting cell (oligodendrocyte or Schwann cell) regulates the axonal phenotype by fine-tuning the ongoing axonal protein synthesis.
\end{abstract}

Key terms: axon, protein synthesis, nerve regeneration, Schwann cell, Wld ${ }^{\mathrm{s}}$.

The nerve has a dual effect upon the skeletal muscle. It regulates what the muscle does (contraction) and what the muscle is (phenotype). Contraction is a reversible short-term change of the cytoplasm triggered by membrane phenomena, without involvement of the nucleus. In contrast, the phenotype results of genetic programs and the phenotype modifications are measured in days. For example, fibrillation of the muscle, which is a typical trophic phenomenon, occurs a few days after denervation and is reduced by inhibition of transcription or translation (Llados and Zapata, 1974).

The phenomena relating to the control of the phenotype have been embraced under the heading of trophism. A contact of the synaptic type is not required. In the nervous system, a non-synaptic trophic effect is illustrated by the development of the myelin sheath, a dependence of the Schwann cell, which is triggered by the axon. We will present evidence that the converse also occurs, namely, that the glial cell regulates the phenotype of the ensheathed axon, which is effected on a local basis. We will consider the microtubular content of axons, their calibers, and their ability to extend sprouts and to synthesize proteins. We also will outline a tentative model for this glia-toaxon control of the phenotype (Fig 1).

\section{GLIAL CELLS CONTROL MICROTUBULES AND CALIBER OF AXONS}

Neurofilaments and microtubules are the major components of the cytoskeleton of the axon. The microtubular density (microtubules $/ \mu \mathrm{m}^{2}$ ) of axons is an inverse function of their caliber (Fig 2), and independent of the myelin sheath (Fadic et al., 1985; Vergara et al., 1991). For a given axonal size, the density is the same irrespective of the length of the axon, the nerve examined, the age of the animal, the developing or regenerating condition of the nerve, the nutritional status, or the species surveyed (Álvarez and Zarour, 1983; Espejo and Âlvarez, 1986; Faúndez and Álvarez, 1986; Faúndez et al., 1989; Saitua and Álvarez, 1988). Nonetheless, we found one 
exception: the spinal root. Motor and sensory axons span from the cord through the root to the peripheral nerve. For axons of equal size, the microtubular density in the root is one half that of intracord or peripheral domains. This holds for axons regardless of whether they are sensory or motor, myelinated or unmyelinated, spinal or cranial (Fadic et al., 1985; Saitua and Álvarez, 1989; López and Álvarez, 1990). Therefore, axoplasmic proteins are arrayed differently in the root as compared to intracord or peripheral trajectories, i.e., the axonal phenotype correlates with the environment, while the neuronal class (motor, sensitive, or sympathetic) is irrelevant.

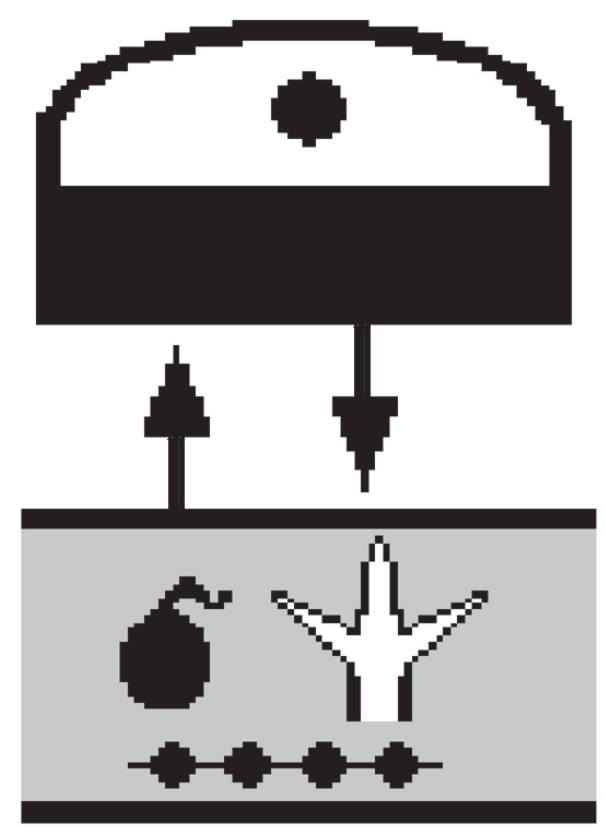

Figure 1. Model axon. The axon (lower part of the diagram) embodies a sprouting program (fork), a destruction program (bomb), and the machinery for protein synthesis (beaded string); in addition, the axon regulates the Schwann cell $(\uparrow)$. Typically, the axon induces the Schwann cell to differentiate. The Schwann cell (upper part of the diagram), in turn, controls the axon $(\downarrow)$. The Schwann cell represses the sprouting program and down-regulates the microtubular content of the axoplasm. In this paper, we will not deal with the destruction program. Modified from Alvarez, 2001.
This correlation requires that the axon "senses" its environment. This hypothesis was tested in the cat using the nodosal ganglion of the vagal nerve. The central branches of the T-shaped axons of nodosal neurons are homologous to dorsal root fibers. They extend about one $\mathrm{cm}$ in the neck before entering into the skull. The microtubular density of these central branches was half that of the peripheral branches of the same neurons, i.e., the asymmetry of these $\mathrm{T}$-axons about its bifurcation was comparable to that of ordinary sensory axons. These central branches were allowed to regenerate along the hypoglossal nerve by means of a surgical anatomosis or, as a control, along its anatomical trajectory. When the central branches regenerated along their anatomical trajectory, the original low microtubular density was found, while upon regeneration along the foreign peripheral nerve, a high density was found (Serra and Álvarez, 1989). Therefore, the phenotype of the axon correlated with the environment, not with the central nature of the branch.

Thus, in the correlation between axonal phenotype and environment, the latter seems to have the upper hand, and the neuronal process gives way. The Schwann cell stands as the best candidate to effect this "environmental" regulation (cf. Court et al., 2004). We assumed that a constitutive axonal program deals with the microtubular density and that the Schwann cell controls the set point of the program. To test this conjecture, Schwann cells were destroyed selectively along a $4 \mathrm{~mm}$ segment of sciatic nerve by inhibiting transcription with actinomycin D. A few days later, only remnants of Schwann cells were seen in the nerve, the axons looked healthy but with an apparent increase of microtubules (Fig 3B, C). The quantitative study revealed that a constant density replaced the inverse correlation between size and microtubular density across the spectrum of sizes, which matched the uppermost value of control axons (smallest class) (Fig 2). This phenomenon also occurred on a strictly local basis, as within a few mm central and distal to the treated site, the fibers were normal (Bustos et al., 1991). We conclude 
that Schwann cells down-regulate the set point of the microtubular program of axons, and for the same reason, the high and constant microtubular density across the size spectrum is the intrinsic set point. The substantial increase of microtubules in a restricted axon segment requires a supplement of proteins. The view that the cell body supplies all axonal proteins cannot explain the local rise of microtubules in a straightforward manner, since this model allows only for redistribution of existing proteins, i.e., accumulation at one point entails depletion at another, which was not observed.

We further studied whether microtubules can be forced to increase exaggeratedly on a local basis. To this end, we administered taxol to the nerve, a drug known to stabilize microtubules. A few days later, the microtubular mass was six fold the original mass, also on a strictly local basis (cf. Fig
3D) (Bustos et al., 1991). Therefore, a local supply of axonal proteins seemed mandatory to account for this new phenotype.

The caliber of the axon is also controlled, on a local basis by the glial cell. In culture, neurons extend neurites that do not surpass a certain size, but upon myelination, they do so (Windebank et al., 1985). In the heart, myelinated fibers present occasionally unmyelinated segments. In this domain, the size of the axon is smaller than the adjacent myelinated domains (Yokota, 1994). The optic nerve axons illustrate the same phenomenon in the central nervous system. They are unmyelinated in the eyeball and up to the lamina cribosa in the optic nerve; thereafter, axons are myelinated. Upon myelination, the cross-sectional area of the optic nerve axons increases by $59 \%$. Interestingly, as the axon enlarges, the
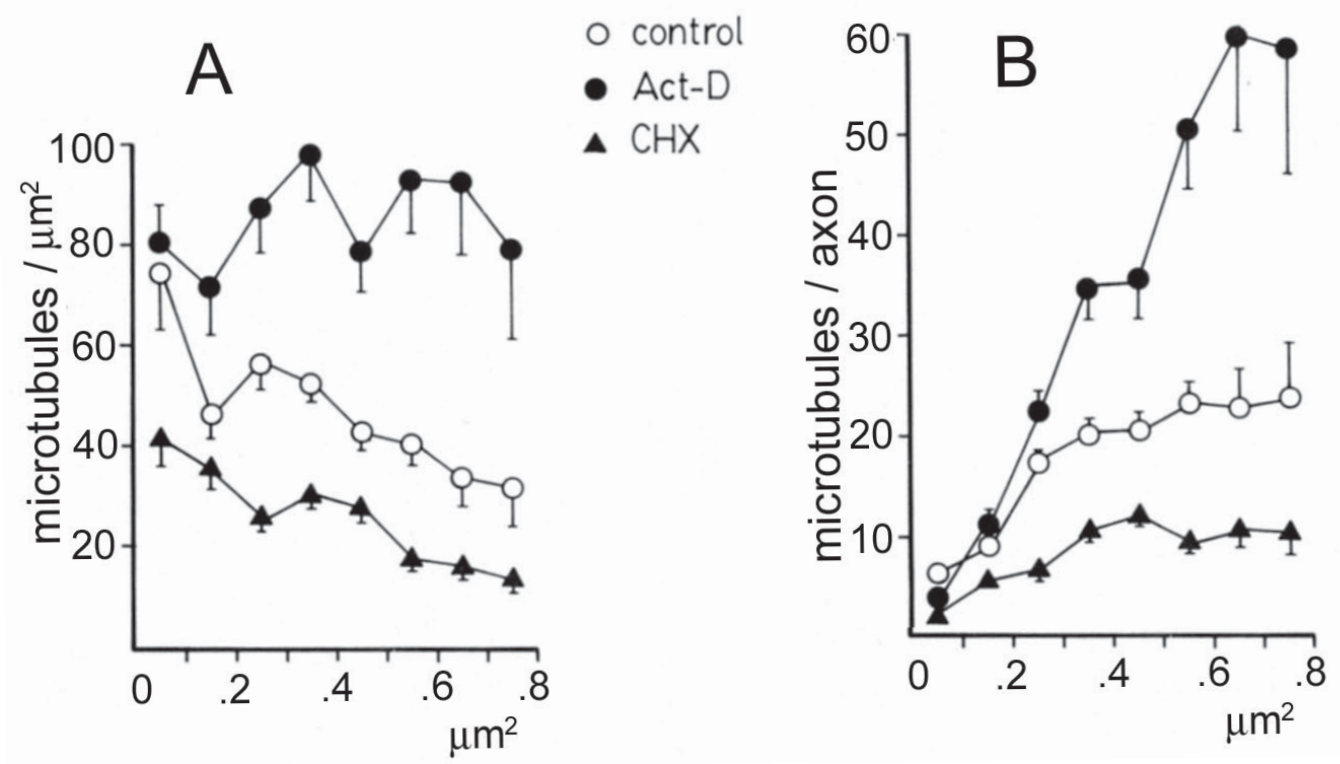

Figure 2. Microtubule quantification in unmyelinated fibres of the sural nerve. Actinomycin D and cycloheximide were administered locally. Ordinates: in A, microtubular density; in B, microtubules per axon. Abscissas: cross sectional area of axons. $\left(0.1 \mu \mathrm{m}^{2}\right.$ interval). Symbols indicate experimental condition. Values are mean plus or minus SEM. In control axons, the microtubular density exhibits an inverse correlation with the size of the axon (A) despite the increase of the number of microtubules with the size (B). Actinomycin destroys the Schwann cell and the microtubular density becomes constant and adjusted to the uppermost value observed in control axons (the smallest class). Cycloheximide reduces the microtubular density across the whole spectrum in the same proportion (A, B). Modified from Bustos et al., 1991. 
microtubular content increases in such a way that the correlation density versus size remains unaffected by myelination (Hernández et al., 1989).

The microtubules and size of axons also are affected by electrical activity. A high and prolonged discharge increases both microtubular content and caliber of axons (Álvarez and Ramírez, 1979; Álvarez et al., 1982; Vergara et al., 1992).

Summing up, the fine anatomy of the axoplasm varies in relation to its history and its neighbors. Connections in the nervous system are often described as "wiring" or "circuitry." These words taken from electrical engineering are misleading as they connote that the elements are passive and static whereas the biological "wire" (axon) is a dynamic element that changes its properties in relation to use and environmental cues.

\section{SPROUTING PROGRAM OF AXONS}

An outstanding feature of neurons is that they extend a process, the axon, which may attain enormous lengths. In large vertebrates, a nerve cell may be several meters long. This process elongates, decides its trajectory, i.e., navigates, branches at certain points and, finally, contacts a target. Development and regeneration are the conditions most used to study phenomena relating to growth in vivo.

We observed that uninterrupted axons of a peripheral nerve extended sprouts when the Schwann cell was destroyed selectively with actinomycin D (Bustos et al., 1991). Both, myelinated (Fig 3C) and unmyelinated axons sprouted. From this, we conclude that the axon has an intrinsic and distributed sprouting program, i.e., the ability to extend sprouts anywhere when the appropriate conditions arise, that is repressed locally, tentatively, by the Schwann cell. In the initial sprouting response, the cell body is not specifically involved.

In our studies with extracellular inhibitors of serine proteases, we observed a sprouting response of unmyelinated and myelinated axons (Álvarez et al., 1992; Moreno et al., 1996). In addition, Schwann cells of the treated segment proliferated (Fig 4A) and destroyed their myelin (Álvarez et al., 1995). Interestingly, axons sprouted even before the destruction of the myelin sheath (Fig 4B). We conjectured that the differentiated Schwann cell represses the sprouting program, while it becomes permissive upon proliferation or dedifferentiation.

In a further step, we considered nerve regeneration under the notions of the sprouting program and its regulation by Schwann cells. A severed nerve regenerates, i.e., the blind end of axons, extend sprouts that lengthen and mature to eventually re-establish the anatomical and functional connections. Here, we will be concerned with the initial event, the extension of sprouts. The growth of axons following a nerve crush presents a delay of 1-2 days. This delay has been ascribed to the time taken by signals going from the lesion up to the cell body, which develops in turn a regenerative response. We will show that this view is likely to be incorrect.

We conjectured that the delay of regeneration could be accounted for by the interplay of the sprouting program of proximal axons and repressive action of the territory to be invaded. In fact, once the nerve is severed, the widow Schwann cells take their time to proliferate and dedifferentiate. In this scenario, the delay of regeneration could reflect the fading away of the repressive action of Schwann cells. Thus, we performed a crush on a segment already treated with protease inhibitors to induce proliferation of Schwann cells and found that the ensuing regeneration had no delay. The same was observed when the distal segment was frozen to destroy all cells in the area (Tapia et al., 1995). Interestingly, the rate of axonal elongation remained normal. These results indicate that the delay of regeneration correlates with the condition of the environment hence the involvement of the cell body becomes an unnecessary construct to account for this delay. On the other hand, the rate of axonal growth, which does belong to the biology of the nerve cell, is unaffected. 


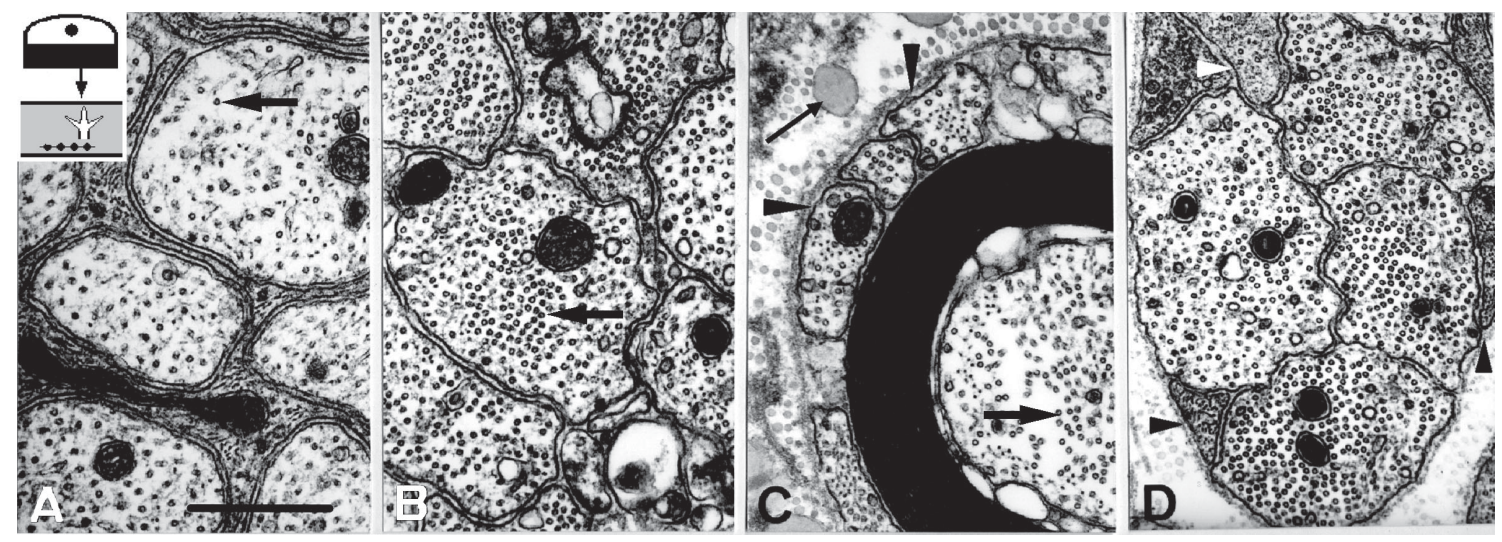

Figure 3. Microtubules and sprouts of nerve fibers treated with actinomycin D and taxol. Diagram shows the actors: The Schwann cell is affected by actinomycin including its regulatory activity $(\downarrow)$. Microtubules, stabilized by taxol, accumulate, calling for a source of microtubular proteins. A. Control unmyelinated bundle: Schwann cell processes surround every axon. Arrow points to a microtubule. B. Unmyelinated bundle: Actinomycin destroyed the Schwann cell (debris interspersed between axons; compare with control Schwann cells in A); axons touch each other extensively, and microtubules (arrow) are abundant (compare with A). C. Actinomycin destroyed the Schwann cell; the myelin sheath, though, remains as there is no Schwann cell to digest it; a crown of sprouts lies between myelin and basal lamina (arrowheads); microtubules (thick arrow) are abundant in the axon; notice a lipid droplet in the extracellular space (thin arrow). D. Unmyelinated bundle after treatment with taxol. Microtubules are crowded in the axoplasm to the point of coalescence. Arrowheads point to Schwann cell processes. Calibration, 0.5 $\mu$ m. Modified from Bustos et al., 1991.

In the Wallerian degeneration slow $\left(\mathrm{Wld}^{\mathrm{s}}\right)$ mice, severed axons present a protracted survival or prolonged delay of degeneration, 3-4 weeks, rather than the usual 1-2 days, and regeneration also is delayed (Lunn et al., 1989). We considered the nerve of the Wlds strain under the notion of the axonal sprouting program and its repression by Schwann cells. In this scenario, the protracted survival of severed Wlds axons prevent the dedifferentiation of the Schwann cells of the distal stump, whereby they remain repressive for the in-growth of axons. We tested this conjecture by crushing a nerve across a segment whose Schwann cells were previously destroyed with actinomycin D. Regeneration of the Wld nerve normalized (Court and Álvarez, 2000). Thus in the Wlds strain, the prolonged delay of regeneration is a consequence of the abnormal environment offered to regrowing axons, while the ability of neurons to grow seems normal.
This far, the sprouting program emerges as an attribute intrinsic to the axon, which is launched as soon as the environment becomes permissive. Since the cell body seems unnecessary to trigger the sprouting response of axons, we conjectured, thus, that axons fully disconnected from their cell bodies should sprout at their blind end, as they embody a sprouting program ready to go. However, ordinary axons degenerate in a day or two after a lesion, which precludes an experimental study of their ability to grow. In contrast, a Wlds nerve, owing to its long survival in situ after a lesion, is a suitable model. In the sciatic nerve of $\mathrm{Wld}^{\mathrm{s}}$ mice, a piece of nerve was excised and the distal stump was fitted with a $5 \mathrm{~mm}$ crush, thus, the distal nerve had two domains in succession: (i) the extended crushed zone, which contained no living Schwann cells, hence it was a territory permissive for axonal growth; followed by (ii) the surviving axons, which embodied the sprouting program (Fig 5, diagram). A few 


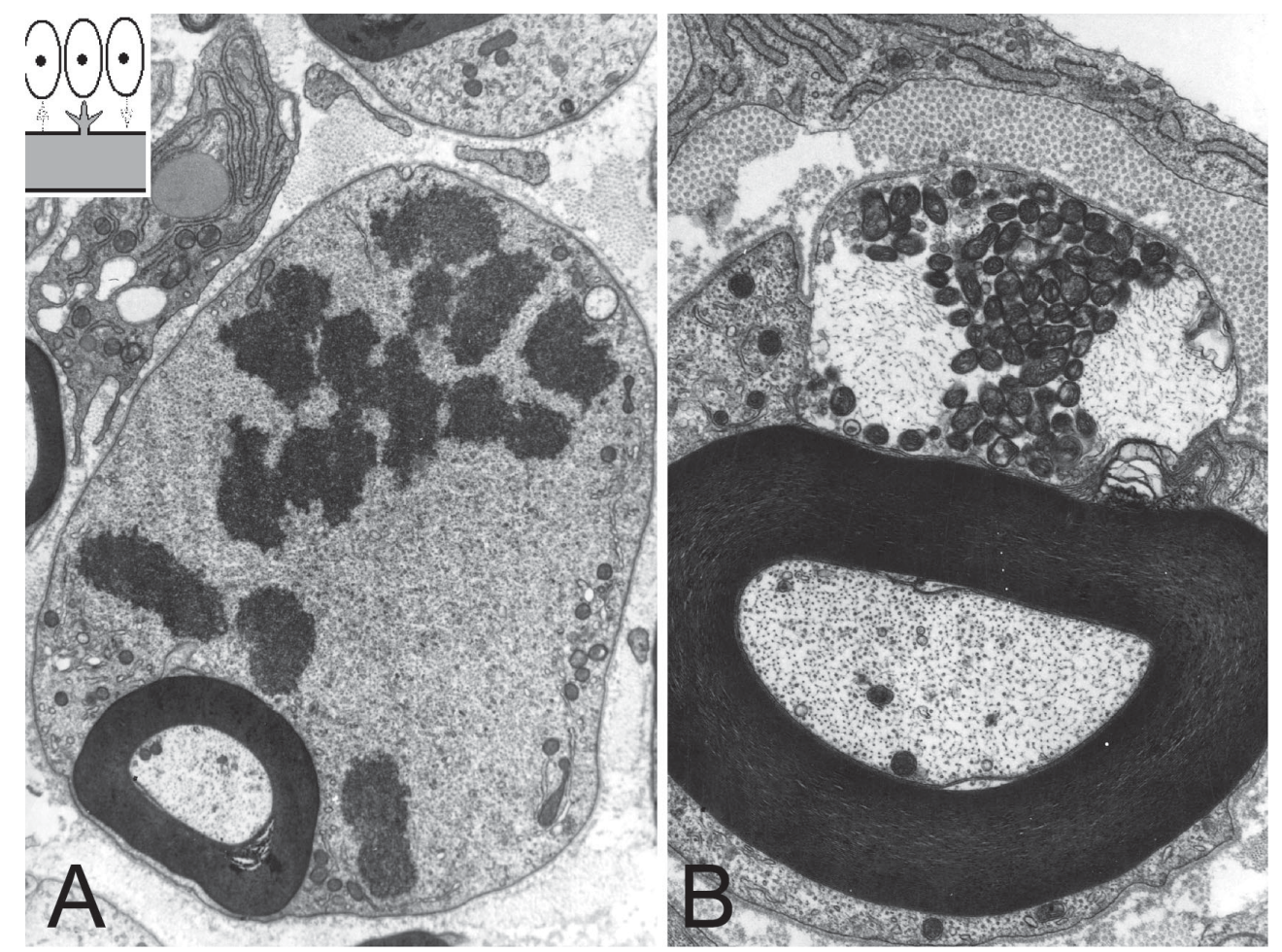

Figure 4. Effect of aprotinin, a protease inhibitor, on axons and Schwann cells. Diagram shows the actors. Aprotinin induce Schwann cells to proliferate and dedifferentiate while the axon extends sprouts. The reciprocal regulation between axon and Schwann cell is lost. A. Myelinated fiber. In the cytoplasm of the Schwann cell, the dark masses are chromosomes, i.e., the cell is proliferating but its myelin sheath is still intact. B. Myelinated fiber. The axon inside the myelin sheath looks normal, while a second axonal profile with a considerable number of mitochondria, a sprout of the former, lies between the myelin and the basal lamina. Modified from Álvarez et al., 1995.

days later, in the extended crush, sprouts were observed with the electron microscope, horseradish peroxidase administered to the surviving axons made its way to the sprouts, and DiI, a dye that does not leave membranes, stained continuously from the site of application to the blind end of axons and to the sprouts emerging from them (Fig 5) (Iñiguez and Álvarez, 1999). Since these axons were disconnected from their cell bodies, the occurrence of sprouts shows beyond any reasonable doubt that axons have a built-in sprouting program that is triggered when the external conditions are appropriated.

In our view, nerve regeneration is a particular case in which the sprouting program of axons is expressed. The interplay of the sprouting program of axons and the regulatory action of glial cells may lead to a wide range of manifestations in physiological conditions and pathological disorders (cf Schmidt et al., 1996; Nien et al., 1998; Court, 2004).

\section{PROTEIN SYNTHESIS IN AXONS}

The phenotype of a cell is the macroscopic array of proteins and other macromolecules. The fact that the phenotype of axons is locally controlled raises the question, among others, for the source of the requisite proteins. There are two competing views concerning the source of axonal proteins. The first is the textbook notion that the cell body supplies most, if not all, proteins to the axon by a slow transport mechanism. This view is untenable unless ad hoc assumptions are 
added time and again. For example, transported proteins should spend years in transit, time enough for complete degradation before reaching their destination (Álvarez and Torres, 1985). The other view claims that the axoplasm synthesizes its own proteins, a view largely ignored-despite the evidence accumulated for fifty years- on the ground that ribosomes have not been observed in the axoplasm. (For a thorough discussion of these views, see Álvarez et al., 2000.)

We have shown above that the microtubular content may increase in a restricted segment, without modification of the content in the adjacent segments. Since the slow transport view allows only for local redistribution of existing proteins, which was not observed, we explored the possibility of local synthesis of proteins as a source to account for these observations. The local administration of two protein synthesis inhibitors, cycloheximide and emetine, to a short span of nerve reduced by half the microtubular content within a week (Fig 2), while the adjacent segments remained normal. Moreover, this reduction was reversible (Bustos et al., 1991). Together, the studies on axonal microtubules strongly suggest that they are locally controlled through regulation of the local supply of protein.

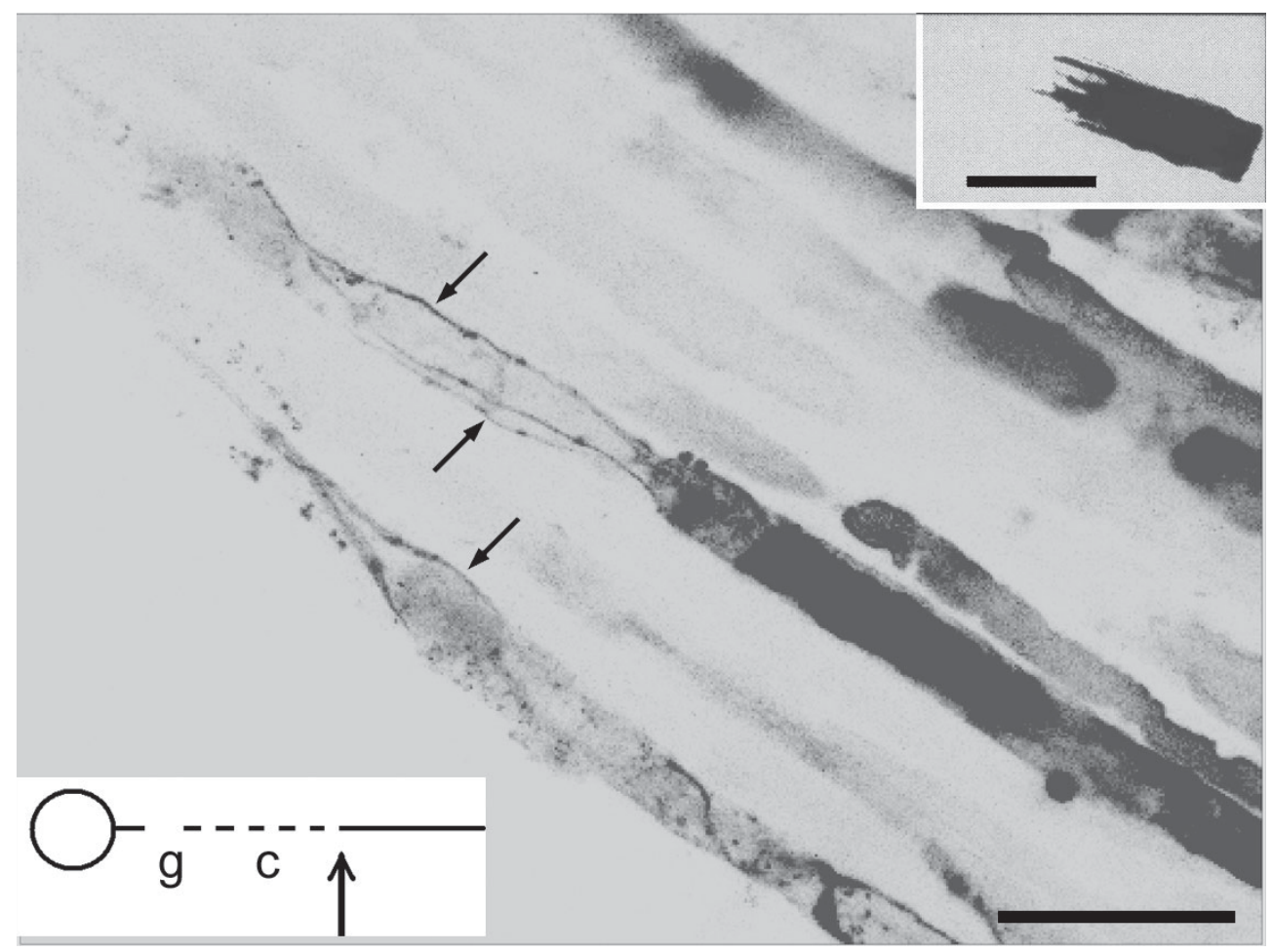

Figure 5. Centralward growth of decentralized Wld ${ }^{\mathrm{s}}$ axons. Diagram is experimental condition. Cell body is to the left; (g) gap in the nerve; broken line is a $5 \mathrm{~mm}$ nerve crush (c); continuous line, undamaged nerve. Arrow indicates the site illustrated by the micrograph, the boundary between crushed and undamaged segments. Nerve examined 5 days after the lesion. DiI was administered to a fresh cut through the undamaged segment after fixation. Inset, whole nerve, extended crush is to the left; calibration, $0.5 \mathrm{~mm}$. Micrograph shows a surviving fiber stained up to the blind end and 3 thin sprouts (arrows) that emerge from it. Below, sprouts also are present (arrow), but the

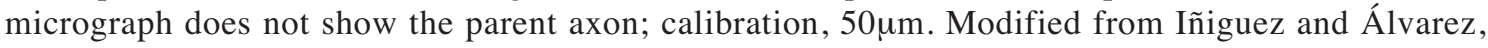
1999. 
Studying Wlds nerves sectioned for over a week under the electron microscope, we found unexpectedly enormous amounts of ribosome-like particles embedded in the axoplasm (Álvarez and Court, 2000). These particles had the size and shape of ribosomes and were observed dispersed in the axoplasm, arrayed in strings as polyribosomes do, attached to membranous cisternae resembling rough endoplasmic reticulum, crowded in membranous sacs (Fig 6A); finally, they incorporated labeled uridine administered after the lesion (Álvarez and Court, 2000; Álvarez, 2001). Further studies with probes for specific ribosomal constituents confirmed the ribosomal nature of these particles (Fig 6B; Court, Álvarez and van Minnen, unpublished). Therefore, axons do contain ribosomes. The cell body could not supply these ribosomes since the nerve was severed while a local RNA source was supported positively by their labeling with a radioactive uridine.

At this point, we want to mention two conditions in which the bulk of the axoplasm increases and its correlation to local synthesis of protein. The elongation of regenerating axons, which imply accretion of axoplasm, is impaired by local inhibition of protein synthesis (Gaete et al., 1998). We mentioned (see above) that hyperactivity increases size and microtubular content of axons; it also increases the incorporation of amino acids into the axoplasm (Eugenin and Álvarez, 1995). This correlation suggests that protein synthesis in axons may be controlled, not only locally, but also along its entire length.

The axoplasm has been shown already to contain tRNAs and mRNAs and to incorporate amino acids into proteins (cf Álvarez et al., 2000) and now ribosomes, hence axons have the machinery for protein synthesis. The transfer of RNAs proposed here sets a new frame for understanding the biology of the nervous system. It becomes clear that the phenotype of the axon is specified incompletely by the genetic programs of the neuron; it has to be finetuned by the associated glial cells. Protein synthesis in the axoplasm becomes a
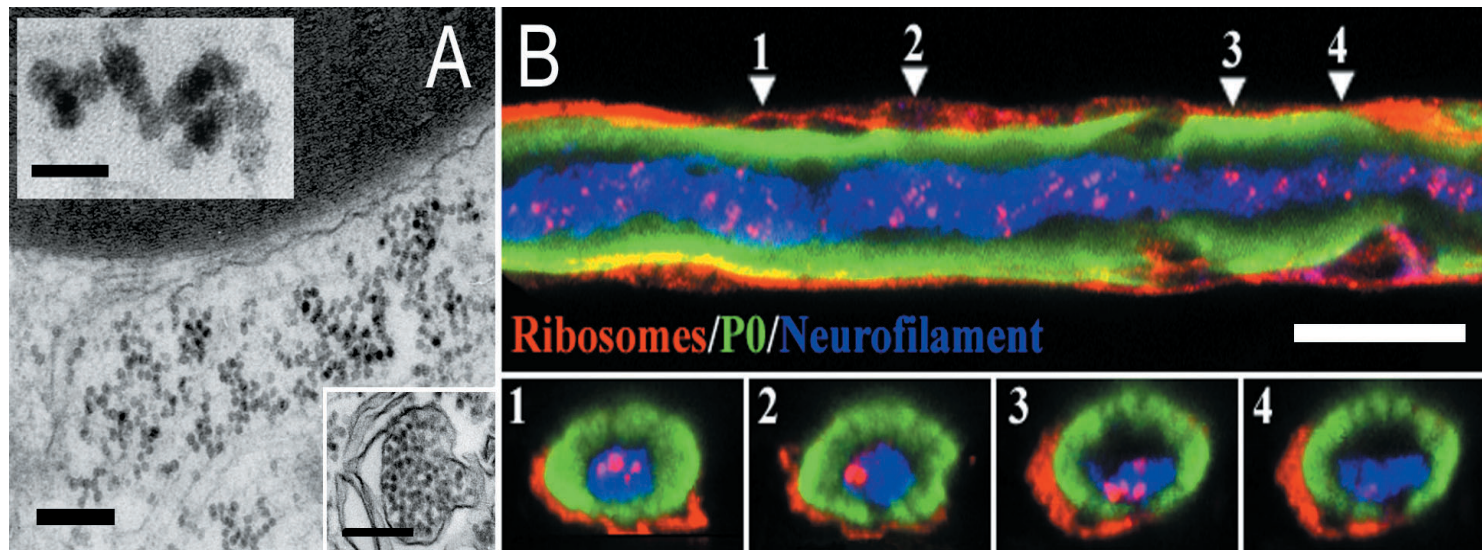

Figure 6. Ribosomes in Wld $^{\mathrm{s}}$ axons decentralized for a week. A. Electron micrograph of a myelinated axon. Myelin and axoplasm are well preserved. In the cortical zone of the axoplasm, abundant particles are present. The morphological features correspond to that of ribosomes. Upper inset, a polyribosome. Lower inset, a membranous sac loaded with particles. Calibration, $0.1 \mu \mathrm{m}$; upper inset, $50 \mathrm{~nm}$; lower inset; $0.1 \mu \mathrm{m}$. B. A myelinated axon stained with an antiserum anti-P protein of ribosomes (red), antibody anti-P0 protein of the myelin (green), and antibody antineurofilament (blue). In the longitudinal axon above, many ribosomal clusters (red puncta) are seen in a field of neurofilament (blue). Lower panels are $\mathrm{Z}$ projections of the longitudinal axon at the corresponding numbers. They show in the transverse plane that the ribosomes (red puncta) are also in a field of neurofilaments (blue), with a preference for the cortex of the axoplasm (Court, van Minnen, unpublished). Calibration, $5 \mathrm{~mm}$. 
pivotal mechanism. We have coined the word "merotrophism" (meros, part) to denote the regulation of the phenotype of a piece of cytoplasm without involvement of the nucleus (Álvarez et al., 2000), as opposed to "trophism." Activity has been shown to be a regulator of the anatomy of the axon and we add merotrophism. We foresee that both will be important for the understanding of the physiology as well as the degenerative disorders of the nervous system and will shed light onto the unexplained functional recoveries following lesions of the central nervous systems.

\section{ACKNOWLEDGEMENTS}

We dedicate this article to Dr. Patricio Zapata. FAC holds an EMBO long-term fellowship.

\section{REFERENCES}

ÁLVAREZ J (2001) The autonomous axon: A model based on local synthesis of proteins. Biol Res 34: 103-109

ÁLVAREZ J, COURT F (2000) Sprouting, growth and regeneration: A novel model of the axon. J Physiol 523P: 51-52

ÁLVAREZ J, RAMÍREZ BU (1979) Axonal microtubules: Their regulation by the electrical activity of the nerve. Neurosci Lett 15: 19-22

ÁLVAREZ J, TORRES JC (1985) Slow axoplasmic transport: A fiction? J Theor Biol 112: 627-651

ÁLVAREZ J, ZAROUR J (1983) Microtubules in short and long axons of the same caliber: Implications for the maintenance of the neuron. Exp Neurol 79: 283-286

ÁLVAREZ J, ARREDONDO F, ESPEJO F, WILLIAMS V (1982) Regulation of axonal microtubules: Effect of sympathetic hyperactivity elicited by reserpine. Neuroscience 7: 2551-2559

ÁLVAREZ J, MORENO RD, LLANOS O, INESTROSA NC, BRANDAN E, COLBY T, ESCH FS (1992) Axonal sprouting induced in the sciatic nerve by the amyloid precursor protein (APP) and other antiproteases. Neurosci Lett 144: 130-134

ÁLVAREZ J, MORENO RD, INESTROSA NC (1995) Mitosis of Schwann cells and demyelination are induced by the amyloid precursor protein and other protease inhibitors in the rat sciatic nerve. Eur J Neurosci 7: 152-159

ÁlVAREZ J, GIUDITTA A, KOENIG E (2000) Protein synthesis in axons and terminals: Significance for maintenance, plasticity and regulation of phenotype. With a critique of slow transport theory. Progress in Neurobiology 62: 1-62

BUSTOS J, VIAL JD, FAÚNDEZ V, ÁLVAREZ J (1991) Axonal microtubules decrease after local inhibition of protein synthesis and increase after inhibition of transcription: A morphometric study in rat sural nerves. Eur J Neurosci 3: 1123-1133
COURT FA (2004) Cellular organisation of peripheral nerve and the neuromuscular junction. Doctoral thesis, Edinburgh University, Edinburgh, UK

COURT F, ÁLVAREZ J (2000) Regeneration of Wld ${ }^{\mathrm{s}}$ nerves is normalized by actimomycin D. Brain Research 867: 1-8

COURT FA, SHERMAN DL, PRATT T, GARRY EM, RIBCHESTER RR, COTTRELL DF, FLEETWOODWALKER SM, BROPHY PJ (2004) Restricted growth of Schwann cells lacking Cajal bands slows conduction in myelinated nerves. Nature 431(7005): 191-5

ESPEJO F, ÁLVAREZ J (1986) Microtubules and calibers in normal and regenerating axons of the sural nerve of the rat. J Comp Neurol 250: 65-72

EUGENÍN J, ÁLVAREZ J (1995) Incorporation of amino acids into the axoplasm is enhanced by electrical stimulation of the fiber. Brain Res 677: 319-325

FADIC R, VERGARA J, ÁLVAREZ J (1985) Microtubules and caliber of central and peripheral processes of sensory axons. J Comp Neurol 236: 258-264

FAÚNDEZ V, ÁLVAREZ J (1986) Microtubules and calibers in developing axons. J Comp Neurol 250: 7380

FAÚNDEZ V, CORDERO ME, ROSSO P, ÁLVAREZ J (1989) Calibers and microtubules of nerve fibers: Differential effect of undernutrition in developing and adults rats. Brain Res 509: 198-204

GAETE J, KAMEID G, ÁLVAREZ J (1998) Regenerating axons of the rat require a local source of proteins. Neurosci Lett 251: 197-200

HERNÁNDEZ C, BLACKBURN E, ÁLVAREZ J (1989) Calibre and microtubules of the nonmedullated and myelinated domains of optic nerve axons. Eur J Neurosci 1: 654-658

IÑIGUEZ A, ÁLVAREZ J (1999) Isolated axons of Wld(s) mice regrow central ward. Neurosci Lett 268: 108-110

LLADOS F, ZAPATA P (1974) Effects of blockers of protein synthesis upon fibrillation due to denervation. Acta Physiol Lat Amer 24: 48-56

LÓPEZ JMA, ÁLVAREZ J (1990) The microtubular pattern changes at the spinal cord-root junction and reverts at the root-peripheral nerve junction in sensory and motor fibres of the rat. Eur J Neurosci 2: 873-878

LUNN ER, PERRY VH, BROWN MC, ROSEN H, GORDON S (1989) Absence of Wallerian degeneration does not hinder regeneration in peripheral nerve fibres. Eur J Neurosci 1: 27-33

MORENO RD, INESTROSA NC, CULWELL AR, ÁLVAREZ J (1996) Sprouting and abnormal contacts of nonmedullated axons, and deposition of extracellular material induced by the amyloid precursor protein (APP) and other protease inhibitors. Brain Res 718: 13-24

NIEN JK, SCHMIDT J, CARTIER L, ÁLVAREZ J (1998) Cerebrospinal fluid of HTLV-1 associated myelopathy patients induces axonal sprouting and Schwann cell proliferation in the rat sciatic nerve. J Neurol Sci 159: 17-24

SAITUA F, ÁlVAREZ J (1988) Do axons grow during adulthood? A study of caliber and microtubules in sural nerve axons of young, mature and aging rats. J Comp Neurol 269: 203-209

SAITUA F, ÁLVAREZ J (1989) Microtubular packing varies along the course of motor and sensory axons: Possible regulation of microtubules by environmental cues. Neurosci Lett 104: 249-252

SCHMIDT J, NIEN JK, SCHERSON A, CAMPOS EO, CARTIER L, ÁLVAREZ J (1996) Segmental demyelination induced by cerebrospinal fluid of progressive spastic paraparesis: correlation with altered proteolytic parameters. Neurosci Lett 214: 1-4 
SERRA M, ÁLVAREZ J (1989) On the asymmetry of the primary branching of vagal sensory axons: Possible role of the supporting tissue. J Comp Neurol 284: 108118

TAPIA M, INESTROSA NC, ÁLVAREZ J (1995) Early regeneration: Repression by Schwann cells and a protease. Exper Neurol 131: 124-132

VERGARA J, REPETTO G, ÁlVAREZ, J (1992) The axonal microtubular density is higher than normal in fibres innervating spastic muscles. J Submicrosc Cytol Pathol 24: 129-134

VERGARA J, SERRA J, SAITUA F, ITURRIAGA R,
ÁLVAREZ J (1991) Axonal microtubules: Comparative anatomy in vertebrates, including man. J Submicrosc Cytol Pathol 23: 357-363

WINDEBANK AJ, WOOD P, BUNGE RP, DYCK PJ (1985) Myelination determines the caliber of dorsal root ganglion neurons in culture. J Neurosci 5: 15631569

YOKOTA R (1984) Occurrence of long non-myelinated axonal segments intercalated in myelinated, presumably sensory axons: Electron microscopic observations in the dog atrial endocardium. J Neurocytol 13: 127-143 